Año LII urtea

N. ${ }^{\circ} 94 . z k$.

2020

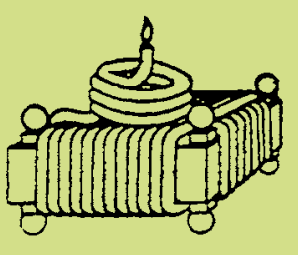

\section{CUADERNOS de Etnología y Etnografía de Navarra}

SEPARATA

\title{
Otros títulos editados en 2019-2020
}




\section{Sumario / Aurkibidea}

\section{Cuadernos de Etnología y Etnografía de Navarra}

Año LII urtea - N. ${ }^{\circ}$ 94. zk. - 2020

\section{ARTÍCULOS/ARTIKULUAK}

Etxe izen zizelkatuak. Ageriko idazkunak etxeetan eta hilobietan

Koldo Colomo Castro

Recardera, oficio de mujer

Ricardo Gurbindo Gil

Aralar mugarriturik (1523-1857)

Jose Luis Erdozia Mauleon

El lecayo, una soka-dantza del siglo XVI

Ricardo Urrizola Hualde

El recuerdo público de una muerte política: historiografía periodística y etnografía de la ritualidad pública (José Luis Cano Pérez, 1949-1977)

Kepa Fernández de Larrinoa, Karlos Irujo Asurmendi, Santiago Martínez Magdalena, Txuri Ollo Gorriti, Cristina Saura Blanco

El Camino de Santiago en Navarra en 1971 a la luz de un informe para su mejora elaborado por la Dirección de Turismo, Bibliotecas y Cultura Popular Fernando Vega López

Reformulación del discurso significativo sociocultural en el entramado fortificado de la Línea P (Valle de Roncal-Navarra) 


\section{Sumario / Aurkibidea}

NOTICIAS/BERRIAK

Joxe Ulibarrena y su pasión por la Etnografía

Elur Ulibarrena Herce

Normas para la presentación de originales / Idazlanak aurkezteko arauak / 


\title{
Otros títulos editados en 2019-2020
}

\author{
DOI: https://doi.org/10.35462/CEEN94.12
}

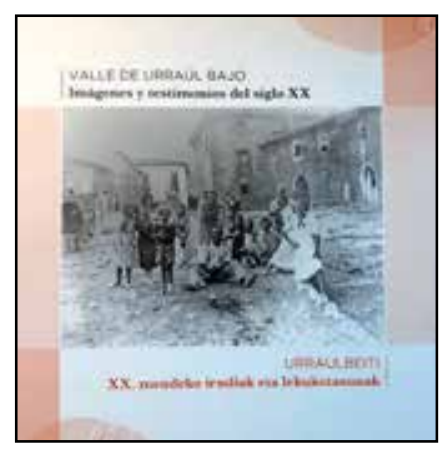

\section{Valle de Urraúl Bajo. Imágenes y testimonios del siglo XX / Urraulbeiti. XX. mendeko irudiak eta lekukotasunak}

AA. VV.

Urraúl Bajo: Ayuntamiento del Valle de Urraúl Bajo, 2020, 276 pp.

Esta obra es fruto del trabajo de recogida de cerca de dos mil fotografías y otros documentos, como cartillas escolares, fichas de guerra, etc., llevado a cabo por el Ayuntamiento del Valle de Urraúl Bajo para preservar y dar a conocer su historia más reciente, para lo cual ha realizado también varias entrevistas a personas mayores de este municipio. A través de estos recuerdos e imágenes se documentan aspectos de la vida tradicional como los trabajos en el campo, juegos, canciones, fiestas, oficios extinguidos, alimentación, indumentaria, religiosidad popular, relaciones entre los pueblos... El libro se completa con varios textos escritos por personas cercanas y conocedoras, por su profesión o por sus vivencias, de esos momentos; sus autores son Natxo Matxin, Alberto Iriarte, María José Beaumont, José Luis Beaumont, Tere Aristu, Pedro Arbeloa, Gemma Piérola, Fernando Hualde y Kati Leatxe.

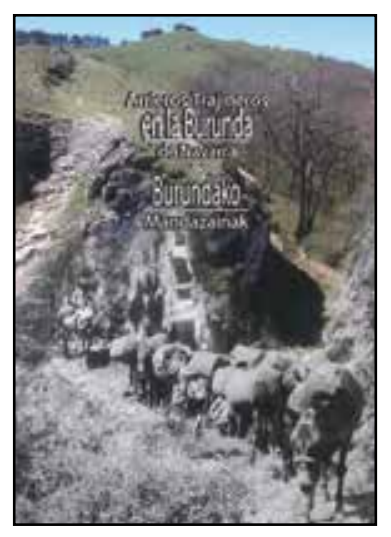

Arrieros-trajineros en la Burunda de Navarra / Burundako mandazainak

ARbizU Gabirondo, Nicolás

Iturmendi: edición del autor, 2019. 168 pp.

Nicolas Arbizu, historiador de Iturmendi, ha realizado un estudio sobre el sector de población que hace doscientos años constituía el grupo más rico y dinámico del valle de Burunda, el de los arrieros, también denominados trajineros. Estos se encargaban del transporte desde los puertos del Cantábrico de productos como aceite de ballena, azúcar, cacao, café, tabaco o telas finas, mientras que desde el valle del Ebro realizaban portes de trigo, vino, aceite, lana, etc. Esta obra de carácter divulgativo analiza las características del oficio de la arriería y describe las rutas y calzadas que utilizaban los trajineros, así como las aduanas, ventas y posadas por las que transitaban. El libro se completa con la historia de las cofradías de San Antón, patrón de los arrieros, que todavía perviven en Urdiain, Iturmendi y Bakaiku. Finalmente, analiza las razones de su decadencia a partir de mediados del siglo XIX y su posterior desaparición. 


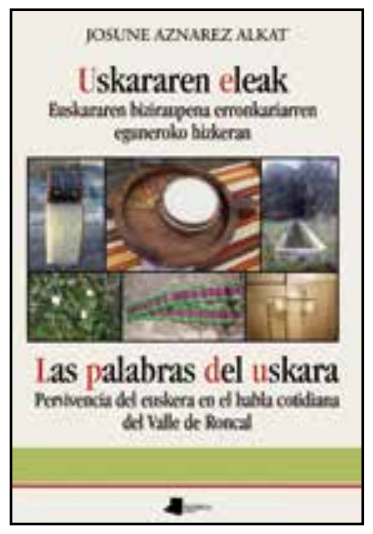

Uskararen eleak. Euskararen biziraupena erronkariarren eguneroko hizkeran / Las palabras del uskara. Pervivencia del euskera en el habla cotidiana del Valle de Roncal AZNAREZ ALKAT, Josune

Pamplona: Pamiela, 2020, 176 pp.

ISBN: 978-84-9172-176-5

Erronkariera XX. mendearen bukaeran galdu zen arren, liburu honen egileak betidanik entzun izan ditu uskarazko hitzak gaztelerazko jardunean txertaturik. Hori dela eta, oihartzun hori biltzea eta jasotzea erabaki du. Elkarrizketak egin ditu Erronkaribarreko herri guztietan eta ele horiek guztiak 19 ataletan sailkatu ditu: animaliak, etxea, ezaugarriak, haur hizkera, janariak, lana eta sentimenduak dira horietako batzuk. Honela, frogatu ahal izan du erronkariera Erronkaribarko zazpi herrietako gaur egungo jardunean eta elkarrizketetan etengabe agertzen dela. Hitzez gain, eta elkarrizketatuen testigantzei esker, beste hainbat gauza dakar liburuak: errezetak, kantak, jolasak, pasadizoak eta ohiturak, besteak beste. Hori guztia ibarreko bizimoduari eta jakinduriari dagokie; hortaz, argitalpen honen balio linguistikoa eta etnografikoa ikaragarria da.

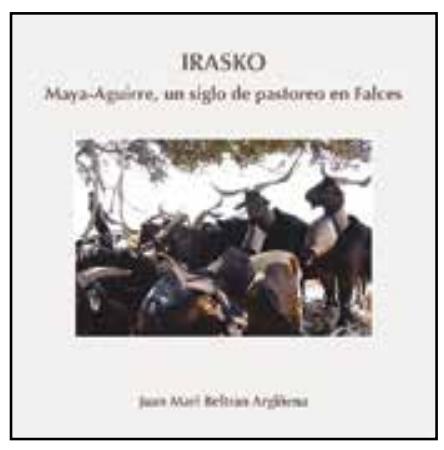

Irasko. Maya-Aguirre, un siglo de pastoreo en Falces BELTRAN ARGIÑENA, Juan Mari

Oiartzun: Soinuenea Fundazioa, 2019, 96 pp + DVD.

Juan Mari Beltran, reconocido musicólogo, decidió grabar asiduamente desde 1994 al pastor de Falces Javi Martínez. Con los años, viendo el volumen y la importancia del material recopilado, la Fundación Soinuenea ha realizado un documental mostrando todo este mundo del pastoreo que ha formado parte de la historia de esta comarca. En este proyecto se presenta la vida pastoril de las familias Maya y Aguirre durante los últimos cien años, mostrando diferentes aspectos de este antiguo oficio como la trashumancia a la Bardena o a la sierra de Andia, el nacimiento de los corderos, el marcaje de las ovejas, el ordeño, los sonidos del rebaño y otros trabajos artesanales de los pastores, incluyendo algunos juguetes e instrumentos sonoros, además de unas jotas relacionadas con el pastoreo. Todo esto constituye un interesante trabajo etnográfico y lo que el autor denomina «un homenaje al pastoreo de la Ribera de Navarra». 


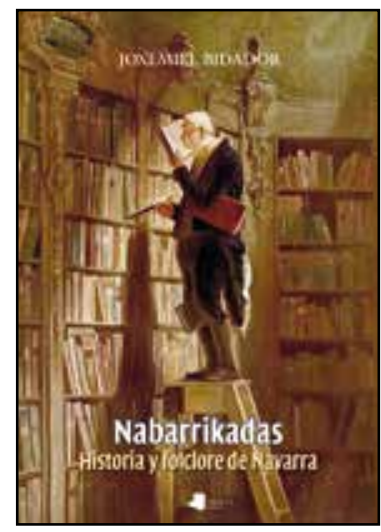

\author{
Nabarrikadas. Historia y folclore de Navarra \\ BIDADOR, Joxemiel \\ Pamplona: Pamiela, 2020, 400 pp. \\ ISBN: 978-84-9172-156-7
}

Gran conocedor de la historia y la etnografía de Navarra, Joxemiel Bidador (Pamplona, 1970-2010) supo combinar magistralmente la investigación rigurosa con la difusión. Su gran capacidad de trabajo le llevó a publicar más de cuatrocientos artículos en periódicos y revistas, como esta recopilación de ochenta artículos seleccionados por el propio autor que fueron editados entre noviembre de 1999 y diciembre de 2002 en Diario de Noticias de Navarra. Este material se presenta dividido en dos partes. Por un lado, un primer bloque de artículos que tituló "Cincuenta viejas historias de Navarra», en donde da a conocer distintas historias, personajes o acontecimientos del devenir histórico de Navarra. La segunda parte de este libro, denominada «Treinta temas de folclore y creencias populares», recoge una serie de textos que bucean en los ritos y costumbres de Navarra. Las labores de edición han sido llevadas a cabo por Idoia Sara y David Mariezkurrena.

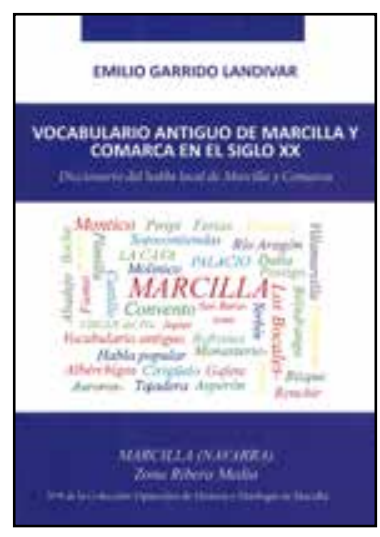

Vocabulario antiguo de Marcilla y comarca en el siglo XX GARRIDO LANDÍVAR, Emilio

Pamplona: Ulzama ediciones, 2020, 320 pp.

ISBN: 978-84-122579-4-6

Emilio Garrido recopila en esta obra más de mil doscientas voces que definen el habla de los vecinos y vecinas de Marcilla, así como de otros pueblos cercanos, durante el siglo pasado. La labor de recogida y publicación ha sido llevada a cabo durante décadas, ya que tras formarse en Etnología de la mano de José Miguel de Barandiaran, empezó a recopilar los saberes de su pueblo -entre ellos el habla popular- a principios de los años setenta. En 2003 publicó una primera aproximación bajo el título Así se hablaba en Marcilla. Vocabulario antiguo de mi pueblo, que ahora ha sido completada con un nuevo trabajo de campo en el que se observa que la mayoría de estas palabras ya en desuso van cayendo en el olvido. La obra se completa con unos capítulos donde se recoge una buena colección de dichos y refranes, la toponimia de la localidad, los motes empleados en Marcilla y unas pocas costumbres y tradiciones populares que ya se han pedido en esta localidad. 


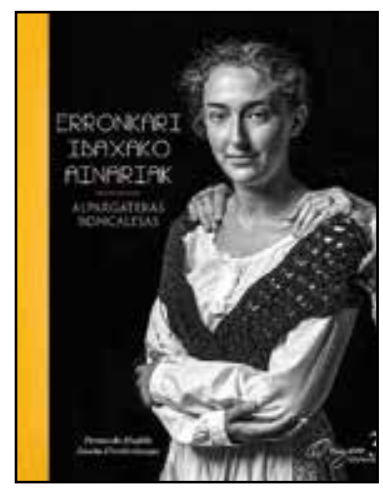

\title{
Erronkari Ibaxako ainariak / Alpargateras roncalesas
} HuALDE, Fernando y URRETAVIZCAYA, Joseba

Tolosa: Xibarit, 2020, 164 pp.

ISBN: 978-84-122816-0-6

Las mujeres representadas en este libro, las alpargateras roncalesas también conocidas popularmente como "golondrinas», salían desde su pueblo cada 7 de octubre, lloviese o nevase, andando, cargadas de juventud, con un hatillo en la mano en el que llevaban la supervivencia de un invierno; recorrían el valle, subían el puerto, atravesaban bosques y barrancos repletos de peligros, cruzaban de un lado a otro el Pirineo..., y todo para pasar el invierno trabajando en las fábricas de alpargatas de Maule, regresando a casa al llegar la primavera. Algunas hasta murieron de frío en el camino, casi niñas, y a pesar de ello socialmente no estaban bien vistas. Silenciosas y silenciadas, en esta obra se trata de salvaguardar la memoria de estas mujeres que hoy son identidad y orgullo del Pirineo. De este modo los textos de Fernando Hualde y las esmeradas fotografías de Joseba Urretavizcaya se convierten en reconocimiento y homenaje a esa generación de mujeres ya desaparecida.

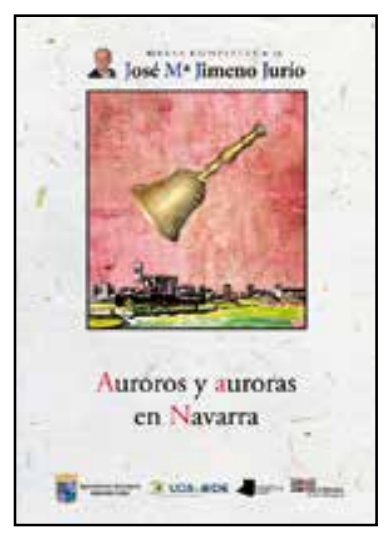

\author{
Auroros y auroras en Navarra \\ JiMENO JURÍO, José María \\ Pamplona: Pamiela, Ayuntamiento de Artajona, Udalbide y Euskara \\ Kultur Elkagoa, 2020, 336 pp. \\ ISBN: 978-84-9172-188-8
}

En los años setenta José María Jimeno Jurío se interesó por las auroras de Navarra en el marco de sus investigaciones etnográficas sobre el calendario festivo. Esta manifestación popular, en esos momentos, estaba sufriendo una profunda transformación, de ahí que este autor se afanara en estudiarla y en recopilar las letras tradicionales. Como investigador riguroso y metódico, Jimeno Jurío emprendió una sistemática e ingente labor de localización, recopilación y documentación de auroras y auroros, que en esta obra se presenta atendiendo a factores como la temática, el origen geográfico o la extracción social de sus protagonistas, por lo que constituye una rica fuente de información para reconstruir aspectos esenciales del cambio cultural y religioso operados en un pasado no muy lejano. Gracias a la labor de edición de su hijo, Roldán Jimeno, este material inédito vez la luz como un nuevo volumen de sus «Obras Completas». 


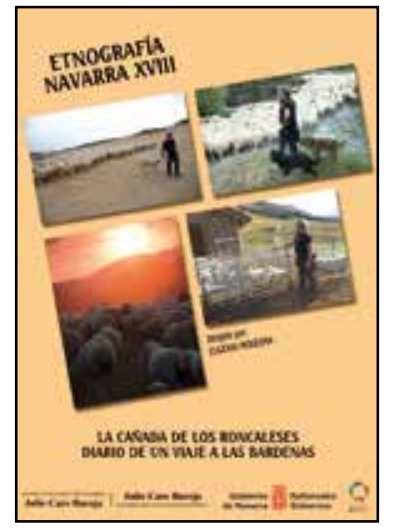

La Cañada de los Roncaleses.

Diario de un viaje a las Bardenas

MONESMA, Eugenio (dir.) y OZKOIDI, Mikel (coord.)

Huesca: Pyrene, Museo Etnológico de Navarra «Julio Caro Baroja», 2020, $51 \mathrm{~min}$.

La Cañada Real de los Roncaleses es la más oriental de las vías de trashumancia de Navarra. En su trayecto de 135 kilómetros de norte a sur esta ruta une los pastos pirenaicos roncaleses de verano en el valle de Belagua con los de las Bardenas, utilizados durante el resto del año, llegando su límite hasta la localidad aragonesa de Tauste. Este nuevo documental de la colección «Etnografía navarra» recoge una práctica que si bien a principios del siglo XX alcanzaba las cien mil ovejas, un siglo más tarde ha quedado reducida a una décima parte. Para ello se ha registrado el día a día trashumante de uno de los pocos rebaños que todavía siguen recorriendo a pie este trayecto entre la montaña y el llano, el del ganadero de Vidángoz Ángel Mari Sanz. Durante varias jornadas se han documentado las labores de este pastor en su camino hacia las Bardenas con un rebaño compuesto por un millar de cabezas de ganado lanar.

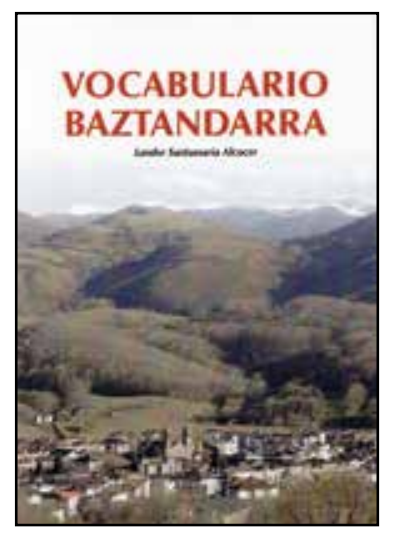

\section{Vocabulario baztandarra}

SANTAMARIA AlCOCER, Lander

Roquetas de Mar, Almería: Círculo Rojo, 2020, 304 pp. ISBN: 978-84-09-16945-0

Esta obra del periodista Lander Santamaria recoge más de mil quinientos vocablos antiguos y actuales del habla popular del valle de Baztan, tratando de aportar una explicación a su origen y significado, y dando a su vez unas pinceladas de su evolución y uso a través del tiempo. A pesar de no estar realizada por un autor experto en lingüística o filología, se trata de una herramienta muy útil para las personas aficionadas a la lingüística y también para quienes deseen conocer cuestiones relacionadas con los usos y costumbres de este rincón del noroeste de Navarra. Tal como indica su subtítulo, este trabajo trata de recoger «el habla popular de los castellanos euskaldunizados y de los euskaldunes castellanizados en el valle de Baztan (y alrededores), 1948-2020", reflejo por lo tanto del devenir histórico y cultural de un territorio, con Elizondo a la cabeza, donde han convivido dos lenguas que han dejado su huella en el habla actual. 